\title{
A FACILE APPROACH TOWARD 8-0-4'-NEOLIGNANS: SYNTHESIS OF THREO-7',8'-DIHYDROMACHILIN D THROUGH JACOBSEN EPOXIDATION
}

\section{UNA FÁCIL APROXIMACIÓN A LOS NEOLIGNANOS 8-0-4': SÍNTESIS DE THREO-7',8'- DIHIDROMACHILIN D A TRAVÉS DE EPOXIDACIÓN DE JACOBSEN}

Freddy A. Bernal ${ }^{1,3} \bullet$ Luis E. Cuca ${ }^{1} \bullet$ Luca Fadini $^{2}$

\section{ABSTRACT}

Neolignans are natural phenylpropanoid dimers with C-O-C linkages. Currently, neolignans remain as important synthetic targets due to their reported biological potential against parasites and fungal infections. Thereof, a new approach for the synthesis of the 8-0-4'-neolignan 7',8'-dihydromachilin D based on Jacobsen epoxidation as key step is described here. This stereoselective synthesis proceeded in only 4 steps in $3.9 \%$ overall yield. Jacobsen epoxidation was firstly optimized regarding to yield and enantioselectivity employing trans-stilbene as model substrate.

Keywords: machilin D, neolignans, Jacobsen epoxidation, synthesis.

Laboratorio de Productos Naturales Vegetales, Departamento de Química, Universidad Nacional de Colombia, Bogotá, Colombia.

2 Scientific Division, Helsinn Advanced Synthesis, Biasca, Switzerland

3 Corresponding author. E-mail: fabernal1230@gmail.com 


\section{RESUMEN}

Los neolignanos son dímeros naturales de los fenilpropanoides con uniones C-O-C. Actualmente, los neolignanos continúan siendo blancos sinténticos importantes debido a su potencial biológico contra parásitos e infecciones fúngicas. Así, se presenta una nueva aproximación a la síntesis de un neolignano 8-0-4' denominado 7',8'-dihydromachilin D, basándose en epoxidación de Jacobsen como paso clave. Esta síntesis estereoselectiva procede en tan solo 4 pasos con un 3,9\% de rendimiento global. La epoxidación de Jacobsen fue optimizada previamente respecto a rendimiento y enantioselectividad empleando trans-estilbeno como sustrato modelo.

Palabras clave: machilin D, neolignanos, epoxidación de Jacobsen, síntesis.

\section{INTRODUCTION}

8-O-4'-type neolignans have been described as secondary metabolites almost exclusive of the Myristicaceae family, and exhibited a plethora of biological properties, including mainly anti-leishmanial (Aveniente et al., 2007), anti-trypanosomal (Nocito et al., 2007), and antifungal (Pinheiro et al., 2004) activities. Virolin (1), surinamensin (2) (Barata et al., 1978), and iryantheral (3) (Bernal and Cuca, 2009) are representative 8-O-4'-neolignan compounds that have been found in Colombian Myristicaceae plants (Fig. 1). In depth, according to the typical structural features of these compounds, determined enantiomers and/or diastereomers have also been isolated from individual species as specific chemomarkers. At this regard, machilin C (4) and D (5) are diastereomers simultaneously isolated from Machilus thunbergii (Shimomura et al., 1987). Machilin C and odoratisol B are enantiomers<smiles>[2H]c1cc(C(O)C(C)Oc2ccc(OC)c(OC)c2)ccc1/C=C/c1cccc(OC)c1</smiles>

$1 \mathrm{R}=\mathrm{H}$

$2 \mathbf{R}=\mathrm{OMe}$<smiles>COc1cc(C(O)C(C)Oc2ccc(C=O)cc2OC)ccc1O</smiles>

3<smiles>COc1cc(C=Cc2ccc(O)c(OC)c2)ccc1O</smiles>

4 erythro

5 threo

Figure 1. Representative 8-O-4' neolignans. 
found in different plant species belonging to the same family (Phan et al., 2006). Similar behavior has been reported to perseal $A$ and $B$ from Persea obovatifolia (Tsai et al., 1996) and to perseal A and iryantheral (Bernal and Cuca, 2009).

Structural simplicity of these neolignans convert them in a convenient model study. Compounds 4 and 5 have been found in different plant species belonging to three different plant families as follows: Machilus odoratissima (Lauraceae) (Phan et al., 2006), Machilus thunbergii (Lauraceae) (Shimomura et al., 1987), Leucas aspera (Labiatae) (Sadhu et al., 2003), Myristica fragrans (Myristicaceae) (Hada et al., 1988), and Iryanthera ulei (Myristicaceae) (Bernal and Cuca, 2009).

The above mentioned properties of the 8-0-4' neolignans have originated great synthetic and biological interests on researchers around the world. Therefore, several methodologies to obtain these neolignans have been reported across different approaches that include propiophenone reduction, aldolic condensation, enantiomeric enrichment of intermediates employing microorganisms, Mitsunobu reaction, or using esters from (S)-lactic acid as starting material by substitution and nucleophilic addition reactions (Sefkow, 2003; Xia et al., 2010a, 2010b; Xia and Wang, 2011; Reddy and Das, 2014). Nevertheless, these methods cannot be extensively scaled due to provide low selectivity (enantioselectivity or diastereoselectivity) and/or involve large number of steps.

Considering the above mentioned limitations to the common synthetic methods of 8-O-4' neolignans, the use of a chiral epoxide as key structural intermediate is proposed here. The new strategy is based on the ring opening of the epoxide previously obtained by Jacobsen epoxidation from a simple and cheap phenylpropene compound-type as starting material. Herein, we report a new approach to the enantioselective synthesis of an 8-O-4' neolignan derivative.

\section{MATERIALS AND METHODS}

\section{General}

${ }^{1} \mathrm{H}-\mathrm{NMR}$ and ${ }^{13} \mathrm{C}-\mathrm{NMR}$ spectra were recorded on a Bruker Avance 400 spectrometer. IR spectra were recorded on a Prestige-21 Shimadzu spectrometer in film on $\mathrm{NaCl}$ window. UV spectra were obtained in a Thermoscientific Evolution 300. HRMS were obtained on a LC-MS-IT-TOF Shimadzu system under direct injection. HPLC separations and quantification were accomplished on a HPLC-UV-DAD Merck-Hitachi system. Yields to epoxidation of trans-stilbene were determined by RP-HPLC using a Phenomenex Ultracarb C30 column (150 x 4.6 mm i.d., $5 \mu \mathrm{m})$. Enantiomeric excesses were determined by NP-HPLC using a Chiralcel OD-H column (250 x $4.6 \mathrm{~mm}$ i.d.). Optical rotation was measured on a Polartronic $E$ Schmidt + Haensch polarimeter equipped with a sodium lamp (589 nm) and $1.00 \mathrm{~mL}$ cuvette. HPLC grade solvents were employed to HPLC separations. Flash column chromatography was performed on silica gel (230-400 mesh) and TLC on silica gel HF ${ }_{254}$ plates. Organic solvents were distilled and dried according standard procedures before use. All reagents were acquired from Hopkin \& Williams Ltd., Acros Organics and Sigma-Aldrich.

\section{Synthesis of (E)-1-(benzyloxy)-2-methoxy-4-(prop-} 1-en-1-yl)benzene (7)

To well stirred solution of $\mathrm{KOH}(21.6 \mathrm{mmol})$ in ethanol $(60 \mathrm{~mL})$ was added dropwise isoeugenol (14.7 mmol). Benzyl bromide $(20.2 \mathrm{mmol}$ ) was then slowly added with vigorous stirring and heated to reflux for $4 \mathrm{~h}$ under nitrogen atmosphere. The reaction mixture was filtered, concentrated in vacuo, and extracted with isopropyl acetate (AcOiPr; $3 \times 15$ $\mathrm{mL})$. The combined organic layers were washed with water $(4 \times 20 \mathrm{~mL})$. The extract was dried over anhydrous $\mathrm{Na}_{2} \mathrm{SO}_{4}$, filtered and concentrated in vacuo. Flash column chromatography of the residue 
gave the compound 7. White amorphous solid. IR (film/ $\mathrm{cm}^{-1}$ ): 3024, 2932, 2855, 1601, 1582, 1510, 1458, $1414,1379,1260,1225,1136,1028,962,854,783$, 737, 696. ${ }^{1} \mathrm{H}-\mathrm{NMR}\left(400 \mathrm{MHz}, \mathrm{CDCl}_{3}\right): 1.89(1 \mathrm{H}, \mathrm{dd}$, $\left.1.4 / 6.6 \mathrm{~Hz}, \mathrm{H}-3)^{\prime}\right), 3.93\left(3 \mathrm{H}, \mathrm{s}, \mathrm{OCH}_{3}\right), 5.17(2 \mathrm{H}, \mathrm{s}$, $\left.\mathrm{OCH}_{2} \mathrm{Ph}\right), 6.13\left(1 \mathrm{H}, \mathrm{qd}, 6.6 / 15.6 \mathrm{~Hz}, \mathrm{H}-2^{\prime}\right), 6.36(1 \mathrm{H}$, dd, $\left.1.4 / 15.6 \mathrm{~Hz}, \mathrm{H}-1{ }^{\prime}\right), 7.55-6.75(\mathrm{~m}, \mathrm{Ar}-\mathrm{H}) .{ }^{13} \mathrm{C}-\mathrm{NMR}$ $\left(100 \mathrm{MHz}, \mathrm{CDCl}_{3}\right): 18.3\left(\mathrm{C}-3^{\prime}\right), 55.9\left(\mathrm{OCH}_{3}\right), 71.1$ $\left(\mathrm{OCH}_{2} \mathrm{Ph}\right), 109.2(\mathrm{C}-3), 114.2(\mathrm{C}-6), 118.5$ (C-5), 124.0 (C-2'), 127.2, 127.7, 128.5, 130.6 (C-1'), 131.7 (C-4), 137.2, 147.3 (C-1), 149.7 (C-2).

\section{Epoxidation of trans-stilbene (11)}

Epoxidation reaction was performed according to literature (Jacobsen et al., 1991; Zhang and Jacobsen, 1991). In brief, a solution of commercial household bleach (Clorox ${ }^{\circledast}, 20 \mathrm{~mL}$ ) was diluted with $0.05 \mathrm{M}$ $\mathrm{Na}_{2} \mathrm{HPO}_{4}$ (30 mL aprox.) up to $\mathrm{pH}$ of 11.3. This solution $(3 \mathrm{~mL})$ was cooled at $4^{\circ} \mathrm{C}$ (ice-water mixture) and then added to a stirred solution of trans-stilbene $(11,0.55$ $\mathrm{mmol})$ in dichloromethane $(1 \mathrm{~mL})$ with $(R, R)$-Jacobsen catalyst $(0.022 \mathrm{mmol})$. Additive or oxidant $(0.044 \mathrm{mmol})$ was then added. The mixture was vigorously stirred and its progress was monitored by TLC during 6-24 $h$ depends on the additive and oxidant employed. After completion, dichloromethane $(15 \mathrm{~mL})$ was added and organic layer separated and washed with water $(4 \times 10$ $\mathrm{mL}$ ). Solvent was dried over anhydrous $\mathrm{Na}_{2} \mathrm{SO}_{4}$ and concentrated under reduced pressure. The residue was submitted to flash column chromatography on silica gel to afford 12 (trans-2,3-diphenyloxirane) (Imuta and Ziffer, 1979). IR (film/ $\mathrm{cm}^{-1}$ ): 3088, 3061, 3032, 2984, 1602, 1495, 1452, 1102, 1071, 1026, 860, 744, 696, 613, 509. NMR signals are presented in Table 2.

Determination of the yield to the epoxidation of trans-stilbene by RP-HPLC

A stock solution of the trans-stilbene epoxide previously isolated and characterized was prepared in methanol. Adequate dilutions of the stock were prepared to give a series of standard solutions in the range of 0.03 to $0.45 \mathrm{mM}$. Each standard solution was independently injected on the RP-HPLC system under optimized chromatographic conditions and peak area was then measured at $228 \mathrm{~nm}$ (maximum absorption wavelength). Calibration curve was built as peak area versus trans-stilbene epoxide concentration $\left(r^{2}=0.9988\right)$.

Each dried and crude reaction product was dissolved in dichloromethane and appropriately diluted. Then those were injected on RP-HPLC system and peak area measured. In order to determine the mass of pure product 12, peak area was interpolated into the calibration curve. Based on the obtained mass, reaction yield was calculated.

Determination of the enantiomeric excess for trans-stilbene epoxide (12) by HPLC

Purified products from epoxidation reaction were dissolved in hexane and submitted to chiral separation on HPLC under previously optimized conditions. Peak areas were measured and employed to calculate the enantiomeric excess.

\section{Synthesis of 2-(4-(benzyloxy)-3-methoxyphenyl)-} 3-methyloxirane (8)

Epoxidation of 7 was accomplished using the same methodology that the above described to 11 although purification was efficiently completed on neutral alumina. Compound 8 was obtained as amorphous yellowish solid. $[\alpha]_{D}^{20}=-11.3^{\circ}$ (c. 0.004; $\mathrm{CH}_{2} \mathrm{Cl}_{2}$ ). IR (film/ $\left.\mathrm{cm}^{-1}\right): 2963,2928,1591,1514,1458$, $1414,1379,1314,1265,1227,1159,1136,1024,843$, 808, 741, 689. ${ }^{1} \mathrm{H}-\mathrm{NMR}\left(400 \mathrm{MHz}, \mathrm{CDCl}_{3}\right): 1.46(3 \mathrm{H}$, $\left.d, 5.2 \mathrm{~Hz}, \mathrm{H}-3^{\prime}\right), 3.05\left(1 \mathrm{H}, d q, 2.0 / 5.2 \mathrm{~Hz}, \mathrm{H}-2^{\prime}\right), 3.55$ $(1 \mathrm{H}, \mathrm{d}, 2.0 \mathrm{~Hz}, \mathrm{H}-1), 3.91\left(3 \mathrm{H}, \mathrm{s}, \mathrm{OCH}_{3}\right), 5.17(2 \mathrm{H}, \mathrm{s}$, $\left.\mathrm{OCH}_{2} \mathrm{Ph}\right), 6.77-6.90(\mathrm{~m}, \mathrm{Ar}-\mathrm{H}), 7.27-7.50(\mathrm{~m}) .{ }^{13} \mathrm{C}-\mathrm{NMR}$ $\left(100 \mathrm{MHz}, \mathrm{CDCl}_{3}\right): 17.7\left(\mathrm{C}-3^{\prime}\right), 55.8\left(\mathrm{OCH}_{3}\right), 58.7(\mathrm{C}-$ $\left.2^{\prime}\right), 59.4\left(\mathrm{C}-1^{\prime}\right), 71.0\left(\mathrm{OCH}_{2} \mathrm{Ph}\right), 108.5(\mathrm{C}-3), 113.9(\mathrm{C}-$ 6), 118.2 (C-5), 127.1, 127.7, 128.4, 130.8 (C-4), 137.0, 
147.9 (C-1), 149.8 (C-2). HRESIMS: $293.0705[\mathrm{M}+\mathrm{Na}]^{+}$ and $271.0848[\mathrm{M}+\mathrm{H}]^{+}$. Calculated for $\mathrm{C}_{17} \mathrm{H}_{18} \mathrm{NaO}_{3}$ : 293.0732 and for $\mathrm{C}_{17} \mathrm{H}_{19} \mathrm{O}_{3}: 271.0872$.

\section{Synthesis of (E)-1-(4-(benzyloxy)-3-} methoxyphenyl)-2-(2-methoxy-4-(prop-1-en-1-yl) phenoxy)propan-1-ol (9)

Isoeugenol $(6,0.74 \mathrm{mmol})$ and $\mathrm{KOH}(1.3 \mathrm{mmol})$ were mixed in ethanol $(3 \mathrm{~mL})$ during $30 \mathrm{~min}$. Subsequently, epoxide $8(0.20 \mathrm{mmol})$ dissolved in ethanol $(1 \mathrm{~mL})$ was dropwise added and the mixture was then heated to reflux for $3 \mathrm{~h}$. Progress of the reaction was monitored by TLC. Reaction was quenched with cold water $(10 \mathrm{~mL})$ and followed by extraction with ethyl ether $(3 \times 15 \mathrm{~mL})$. Organic layer was washed with $0.2 \mathrm{~N}$ $\mathrm{NaOH}(3 \times 10 \mathrm{~mL})$ and water $(3 \times 10 \mathrm{~mL})$. Finally, it was dried over anhydrous $\mathrm{Na}_{2} \mathrm{SO}_{4}$ and concentrated under reduced pressure. The residue was submitted to flash column chromatography to afford 9. Yellowish oil. [a] $\mathrm{D}^{20}=-10.0^{\circ}$ (c. 0.002; $\mathrm{MeOH}$ ). IR (film/ $\mathrm{cm}^{-1}$ ): 3450, 2932, 1599, 1510, 1458, 1416, 1379, 1261, 1225, 1134, 1028, $856,812,741 .{ }^{1} \mathrm{H}-\mathrm{NMR}\left(400 \mathrm{MHz} \mathrm{CDCl}_{3}\right): 1.24(3 \mathrm{H}, \mathrm{d}$, $6.4 \mathrm{~Hz}, \mathrm{H}-3), 1.87\left(3 \mathrm{H}, d d, 1.5 / 6.6 \mathrm{~Hz}, \mathrm{H}-3^{\prime \prime \prime}\right), 3.90(3 \mathrm{H}$, s), $3.92(3 \mathrm{H}, s), 4.09(1 \mathrm{H}, \mathrm{m}, \mathrm{H}-2), 4.89(1 \mathrm{H}, \mathrm{d}, 4.5 \mathrm{~Hz}$, $\mathrm{H}-1), 5.16(2 \mathrm{H}, \mathrm{s}), 6.11\left(1 \mathrm{H}, \mathrm{qd}, 6.6 / 15.7 \mathrm{~Hz}, \mathrm{H}-2^{\prime \prime \prime}\right), 6.31$ $\left(1 \mathrm{H}, d d, 1.5 / 15.7 \mathrm{~Hz}, \mathrm{H}-1^{\prime \prime \prime}\right)$, 6.69-7.06 (m, Ar-H), 7.30$7.50(\mathrm{~m}, \mathrm{Ar}-\mathrm{H}) .{ }^{13} \mathrm{C}-\mathrm{NMR}\left(100 \mathrm{MHz} \mathrm{CDCl}_{3}\right): 17.7$ (C-3), $18.3\left(\mathrm{C}-3^{\prime \prime \prime}\right), 55.9\left(\mathrm{OCH}_{3}\right), 56.0\left(\mathrm{OCH}_{3}\right), 70.6(\mathrm{C}-1), 71.0$ $\left(\mathrm{OCH}_{2} \mathrm{Ph}\right), 86.9(\mathrm{C}-2), 109.3\left(\mathrm{C}-2^{\prime}\right), 110.6\left(\mathrm{C}-3^{\prime \prime}\right), 113.6$ (C-5), 118.1 (C-5'), 118.7 (C-6), 119.6 (C-6"'), 124.5 (C$\left.2^{\prime \prime \prime}\right), 127.3,127.8,128.5,130.5$ (C-1'"'), 131.3 (C-1'), 132.8 (C-4"'), 137.1, 146.8 (C-1'), 147.9 (C-4'), 149.7 (C3'), 150.5 (C-2'). HRESIMS: 457.1965 [M+Na] ${ }^{+}$. Calculated for $\mathrm{C}_{27} \mathrm{H}_{30} \mathrm{NaO}_{5}: 457.1991$.

Synthesis of (E)-1-(4-(hydroxy)-3-methoxyphenyl)2-(2-methoxy-4-(prop-1-en-1-yl)phenoxy)propan1-ol (10)

Compound $9(0.020 \mathrm{mmol})$ was dissolved in methanol $(3 \mathrm{~mL})$ and mixed with $\mathrm{Pd} / \mathrm{C}$ catalyst $(10 \%)$.
This mixture was submitted to reaction with hydrogen overnight at room temperature. The crude was filtered and concentrated in vacuo. Flash column chromatography of the residue gave 10 . Colorless oil. ${ }^{1} \mathrm{H}-\mathrm{NMR}\left(400 \mathrm{MHz}, \mathrm{CDCl}_{3}\right)$ : $0.91(3 \mathrm{H}, t, 7.3 \mathrm{~Hz}$, $\left.\mathrm{H}-3^{\prime \prime \prime}\right), 1.00(3 \mathrm{H}, \mathrm{d}, 6.3 \mathrm{~Hz}, \mathrm{H}-3), 1.58\left(2 \mathrm{H}, \mathrm{m}, \mathrm{H}-2^{\prime \prime \prime}\right)$, $2.49\left(2 \mathrm{H}, t, 7.5 \mathrm{~Hz}, \mathrm{H}-1^{\prime \prime \prime}\right), 3.89\left(6 \mathrm{H}, \mathrm{bs}, 2 \times \mathrm{OCH}_{3}\right)$, $4.06(1 \mathrm{H}, m, \mathrm{H}-1), 4.39(1 \mathrm{H}, d, 8.3 \mathrm{~Hz}, \mathrm{H}-2), 5.63(1 \mathrm{H}$, s, OH), $6.52\left(1 \mathrm{H}, b d, 7.5 \mathrm{~Hz}, \mathrm{H}-5^{\prime \prime}\right), 6.58(1 \mathrm{H}, d, 8.0$ $\left.\mathrm{Hz}, \mathrm{H}-6^{\prime \prime}\right), 6.70(1 \mathrm{H}$, bs, H-3'), $6.84(1 \mathrm{H}$, bd, 8.3, H-6'), $6.89\left(1 \mathrm{H}, d, 8.1 \mathrm{~Hz}, \mathrm{H}-5^{\prime}\right), 6.94\left(1 \mathrm{H}, \mathrm{bs}, \mathrm{H}-2^{\prime}\right)$. $\left.{ }^{13} \mathrm{C}-\mathrm{NMR}\left(100 \mathrm{MHz}^{\mathrm{CDCl}}\right)_{3}\right) 13.8$ (C-3'"'), 17.9 (C-3), $24.6\left(\mathrm{C}-2^{\prime \prime \prime}\right), 37.8\left(\mathrm{C}-1^{\prime \prime \prime}\right), 55.7\left(\mathrm{OCH}_{3}\right), 56.0\left(\mathrm{OCH}_{3}\right)$, 71.6 (C-1), 91.3 (C-2), 109.2 (C-2'), 112.0 (C-3'"), 114.1 (C-5'), $118.9\left(\mathrm{C}-6^{\prime \prime}\right), 120.5\left(\mathrm{C}-5^{\prime \prime}\right), 120.8\left(\mathrm{C}-6^{\prime}\right), 131.1$ (C-1'), 137.9 (C-4' '), 145.6 (C-4'), 146.0 (C-1''), 146.8 (C-3'), 150.3 (C-2''). HRESIMS: $369.1642[\mathrm{M}+\mathrm{Na}]^{+}$. Calculated for $\mathrm{C}_{20} \mathrm{H}_{26} \mathrm{NaO}_{5}: 369.1678$.

\section{RESULTS AND DISCUSSION}

\section{General synthetic strategy}

Neolignans are a great group of secondary plant metabolites related to shikimic acid pathway. In depth, neolignans are the product of the oxidative coupling of two phenylpropanoid units (formed by C-O-C' linkages). Compounds 4 and 5 (Fig. 1) are 8-O-4' neolignans in which the two phenylpropanoid units are the same, allowing establishing them as derived from isoeugenol. The compound 7',8'-dihydromachilin $D(10)$, a derivative of 5 , was selected as model target here. The synthetic route to 10 is illustrated in Fig. 2. The present approach was based on ring opening of an epoxide as key intermediate. In order to accomplish an asymmetric synthesis, chiral epoxide was required. In the first step, commercial available isoeugenol was protected by benzylation. Second step was based on formation of a chiral epoxide by employing Jacobsen's catalyst. At this level, trans-stilbene (11) can be employed as simple 


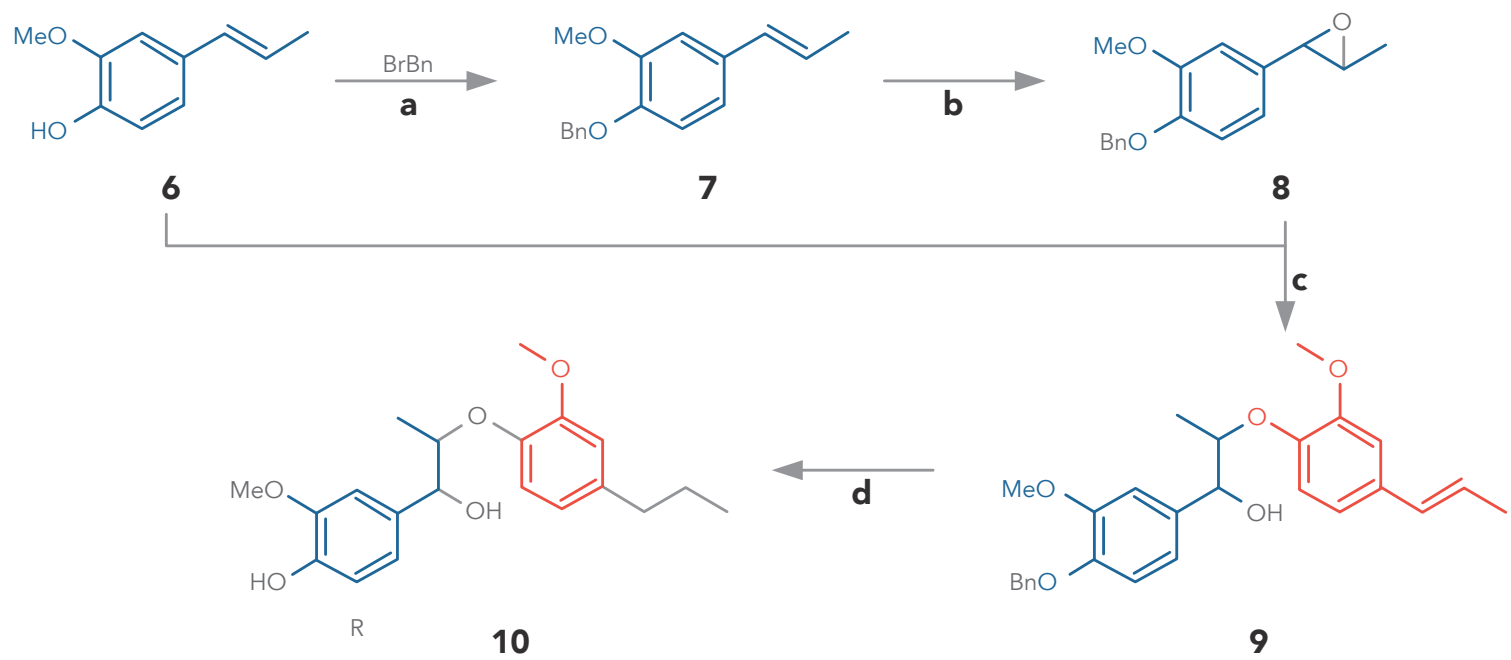

Figure 2. Synthetic route to $7^{\prime}, 8^{\prime}$-dihydromachilin D. a) $\mathrm{KOH} / \mathrm{EtOH}$, reflux; b) $(R, R)$-Jacobsen's catalyst/ $\mathrm{CH}_{2} \mathrm{Cl}_{2}$ and $\left.\mathrm{NaClO}, 4^{\circ} \mathrm{C} ; \mathrm{c}\right) \mathrm{KOH} / \mathrm{EtOH}$, reflux; d) $\mathrm{H}_{2}$ and $\mathrm{Pd} / \mathrm{C}$, r.t., overnight.

trans- model substrate to accomplish the optimization of the catalytic reaction conditions. Ring opening epoxide by isoeugenolate salt was the next step in the proposed route. Finally, reductive hydrogenolysis reaction was carried out to achieve 10 . Herein, isoeugenol (6) was selected as starting material according to its commercial availability and low cost.

\section{Benzylation of 6}

The first step in the synthesis of the 8-0-4' neolignan was the protection of the hydroxyl group into the structure of isoeugenol 6 (Fig. 2). Compound 6 was submitted to benzylation by nucleophilic substitution of benzyl bromide under three previously reported conditions (Table 1). In spite of potassium carbonate have been reported as common use base in benzylation (Gu et al., 2000; Barrero et al., 1998; Buchi et al., 1967), it was not able to accomplish successfully the reaction on 6 (entry 1 , Table 1). The addition of molecular sieve together with temperature increasing was not efficient either. Since base strength was not sufficient to deprotonate the phenolic hydroxyl group, more drastic conditions were required (entry 3, Table 1; Pond and Beers, 1897). Potassium hydroxide in ethanol was then used obtaining acceptable yield percentage.

\section{Epoxidation of trans-stilbene}

The selected epoxidation process in the present research corresponded to that known as Jacobsen epoxidation, which consist in reaction of an olefin with a terminal oxidant in presence of a chiral [Mn(salen)] complex (Jacobsen et al., 1991; Zhang and Jacobsen, 1991). Several terminal oxidants and additives have been used to improve the yields and/

Table 1. Benzylation of $\mathbf{7}$ under different reaction conditions.

\begin{tabular}{cccc}
\hline Entry & Reagent & Solvent & $\begin{array}{c}\text { Yield } \\
(\%)\end{array}$ \\
\hline 1 & $\mathrm{~K}_{2} \mathrm{CO}_{3}$ & Acetone & 17.3 \\
\hline 2 & $\mathrm{~K}_{2} \mathrm{CO}_{3}+\mathrm{MS} 4 \AA$ & Toluene & 18.1 \\
\hline 3 & $\mathrm{KOH}$ & Ethanol & 80.0 \\
\hline
\end{tabular}




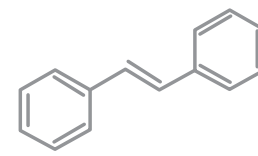

11

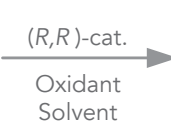

Solvent
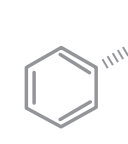

12
Figure 3. Epoxidation reaction of trans-stilbene.

or enantioselectivities (Skarżewski et al., 1995; Bahramian et al., 2006; Zhang et al., 1990; Zheng et al.; 2004; Clarke et al., 2005; Liao and List, 2009). There are a great number of reports about application of Jacobsen epoxidation to broad range of cis substrates, but poor results to trans substrates respect to enantioselectivities and yields have been found (McGarrigleand Gilheany, 2005). So, it was mandatory to find optimized reaction conditions for the epoxidation of the compound 6. To accomplish it, trans-stilbene (11) was used as a simple trans model substrate. The general epoxidation reaction to the compound 11 is shown in Fig. 3. Relative configuration of the isolated product 12 was defined as trans by comparing its NMR assignments with those previously reported to cis and trans products (Table 2).

Due to low yields were observed in preliminary assays of the Jacobsen epoxidation to 11, quantification of 12 was carried out by external standard

Table 2. Configuration assignment of $\mathbf{1 2}$ by NMR.

\begin{tabular}{ccccccc}
\hline \multirow{2}{*}{$\begin{array}{c}\text { Posi- } \\
\text { tion }\end{array}$} & \multicolumn{2}{c}{$\begin{array}{c}\text { trans- } \\
\text { epoxide* }\end{array}$} & \multicolumn{2}{c}{$\begin{array}{c}\text { cis- } \\
\text { epoxide* }\end{array}$} & \multicolumn{2}{c}{$\begin{array}{c}\text { Isolated } \\
\text { product }\end{array}$} \\
\cline { 2 - 8 } & $\delta_{\mathrm{C}}$ & $\delta_{\mathrm{H}}$ & $\delta_{\mathrm{C}}$ & $\bar{\delta}_{\mathrm{H}}$ & $\bar{\delta}_{\mathrm{C}}$ & $\bar{\delta}_{\mathrm{H}}$ \\
\hline $\mathrm{C} \alpha$ & 62.9 & $3.84(\mathrm{~s})$ & 59.9 & $4.34(\mathrm{~s})$ & 62.8 & $3.87(\mathrm{~s})$ \\
\hline 1 & 137.2 & & 134.5 & 137.1 & \\
\hline 2,6 & 125.6 & & 126.9 & 125.5 & \\
\hline 3,5 & 128.6 & 127.9 & 128.5 & \\
\hline 4 & 128.4 & & 127.5 & & 128.3 & \\
\hline
\end{tabular}

* From literature (Imuta and Ziffer, 1979).
HPLC procedure. Optimal separation conditions were achieved under acetonitrile-water gradient for a representative reaction mixture (Fig. 4). The corresponding calibration curve is shown in Fig. 5. Diastereomeric ratio was also determined to the reaction crude products by ${ }^{1} \mathrm{H}-\mathrm{NMR}$. The signals were compared with those previously reported (Imuta and Ziffer, 1979) and let us to establish a trans/cis ratio major than 95\%. In order to determine the enantiomeric excesses (ee) of the obtained epoxide 12, chromatographic conditions were optimized employing a chiral column and a racemic mixture. This racemate was obtained by epoxidation reaction with [Mn(salen)Cl] complex instead of chiral Jacobsen complex. A representative HPLC profile for ee determination is shown in Fig. 6.

Table 3 shows the different conditions attempted in the epoxidation of 11 . It can be seen that yields were moderate (up to $68 \%$ ), whereas the ee's were low in all cases (up to 20\% ee). In entries 1 and 10 (Table 3), only Jacobsen catalyst and an oxidant $\left(\mathrm{H}_{2} \mathrm{O}_{2}\right.$ and $\mathrm{NaOCl}$, respectively) were used. However, ineffectiveness of hydrogen peroxide as terminal oxidant in the epoxidation of 11 was found. Some additives were then employed in this reaction according to their highly frequent uses in this catalytic reaction (Skarżewski et al., 1995; Bahramian et al., 2006; Zhang et al., 1990; Zheng et al.; 2004; Clarke et al., 2005). The addition of ammonium acetate or imidazol (entries 2-6, Table 3) decreased the yields, accompanied by decreasing of enantioselectivity. The use of pyridine as additive (entries 7-9, Table 3) gave yields around 50\%, although ee was closed to $10 \%$. The yield was slightly increased when pyridine excess was employed (entry 8, Table 3).

Imidazole have also been used as additive in Jacobsen epoxidation due to its trans effect on the $\mathrm{Mn}$ (salen) complex that bring to $\mathrm{Mn}=\mathrm{O}$ bond enlargement and reactivity is then increased. Nevertheless, coordination of imidazole to manganese 


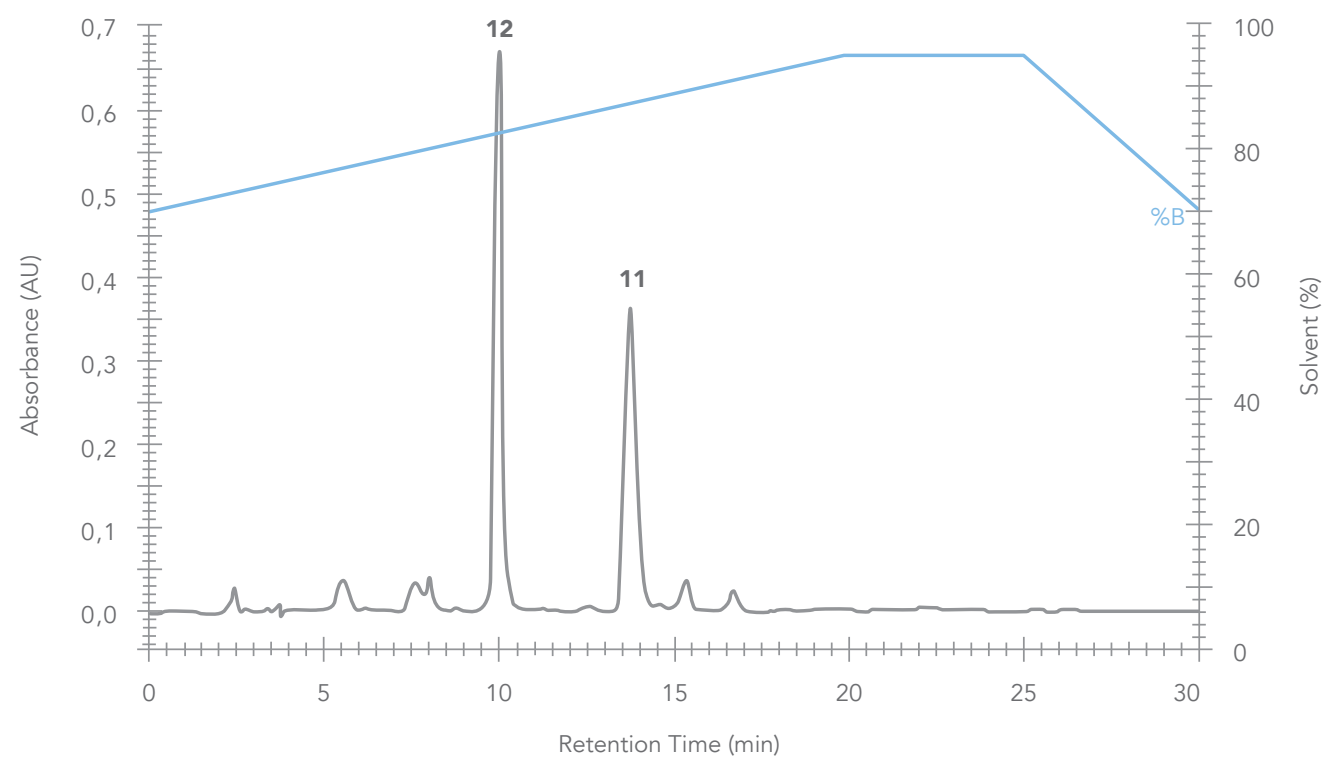

Figure 4. RP-HPLC profile for crude reaction mixture from epoxidation of 11. Phenomenex Ultracarb ODS C30 column (150 x $4.6 \mathrm{~mm}$ i.d., $5 \mu \mathrm{m}$ ); gradient elution with $\mathrm{MeCN}$-water mixture (blue line).

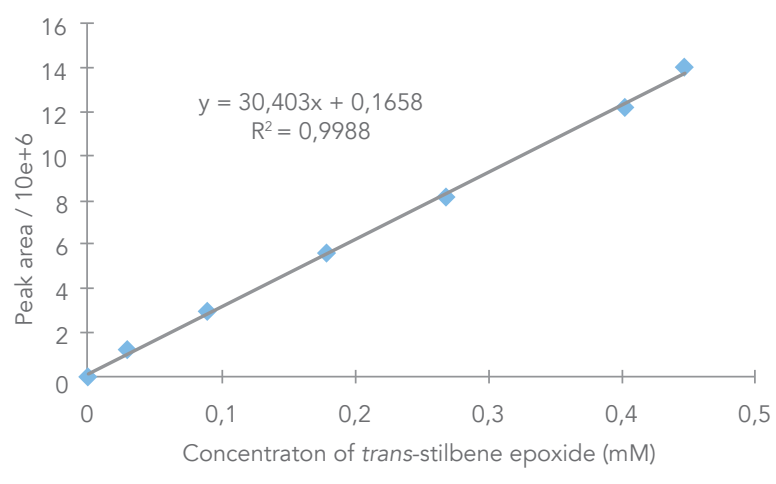

Figure 5. Calibration curve for the quantification of 12 by RP-HPLC.

entails conformational changes in the catalyst which can be attributed as responsible of steric hindrance that causes the poor observed results (Khavrutskii et al., 2004). Pyridine should act in similar way to imidazole (pyridine is $\sigma$-donor and $\pi$-acceptor ligand (Miessler and Tarr, 2004)). The present results let to consider a differential reaction mechanism in Jacobsen epoxidation according to olefin configuration.
The performance of Jacobsen epoxidation to compound 11 (Table 3) can be explained according to observations of Katsuki and collaborators (McGarrigle and Gilheany, 2005; and references cited herein). Moreover, different proposed conformations of $[\mathrm{Mn}(\mathrm{salen})]$ complexes play an important role in the enantioselectivity (McGarrigle and Gilheany, 2005) and even have been studied by means of theoretical calculations (Cavallo and Jacobsen, 2003; Khavrutskii et al., 2004). These conformations let us attribute the obtained ee's to the poor asymmetric induction established by the Jacobsen-catalyst for trans-substrate. However, favorable conformation to epoxidation of 11 could be achieved by chemical interaction of the catalyst with particular additives.

Ionic liquids have been reported as versatile solvents and excellent co-catalysts in organic as well as transition metal catalyzed reactions (Zhao et al., 2002; Baudequin et al., 2003; Welton, 2004; Song et al., 2005; Durand et al., 2007; Pârvulescu and Hardacre, 


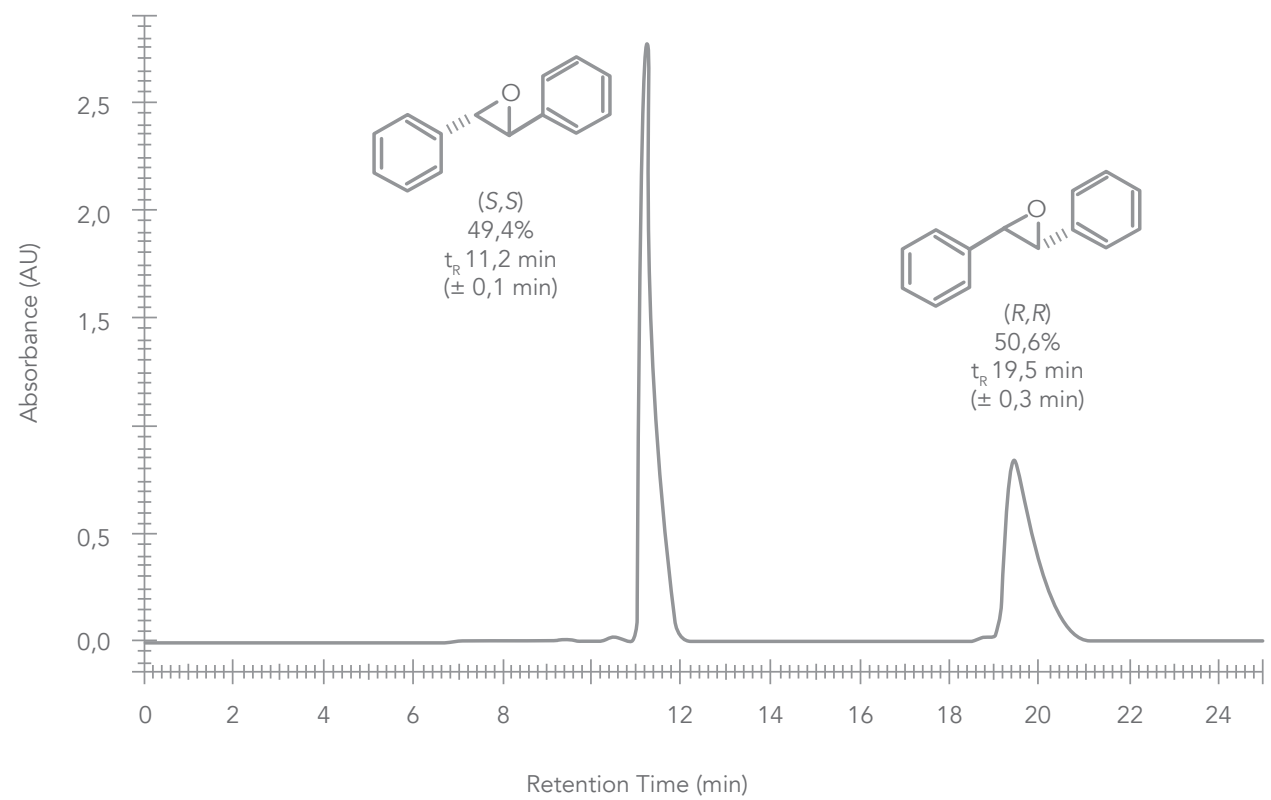

Figure 6. Chiral HPLC profile for the racemate of 12. Chiralcel OD-H column ( $250 \times 4.6 \mathrm{~mm}$ d.i.); isocratic elution with n-Hexane-IPA (9:1). Assignments were based on literature (Chang and Sharpless, 1996).

2007), including Jacobsen epoxidation (Song and Roh, 2000; Kumar, 2007; Pinto et al., 2008; Tang et al., 2008). In general, the use of ionic liquids as solvent (entries 11-17, Table 3) showed low yields (up to $29.5 \%$ ) and very low enantioselectivities too (up to $15 \%$ ee). Combined use of ionic liquids with organic solvent brought to acceptable yield (entry 14, Table 3) but enantioselectivity was decreased. For his part, [OPIC] $\left[\mathrm{BF}_{4}\right]$ (entry 11, Table 3) demonstrated to be able to increase the enantioselectivity of the reaction when compared with the most of the entries in Table 3 , although it was smaller than that obtained with conventional method without additives (entry 10, Table 3). Increase in yield was achieved by pyridine addition on [OPIC] $\left[\mathrm{BF}_{4}\right]$ medium (entry 12, Table 3). Other ionic liquids were employed without favorable results (entries 15-17, Table 3). In spite of results, cisolefin epoxidation in ionic liquids has been reported as only comparable with that in organic solvents as far as conversion and enantioselectivity is concerned.

\section{Epoxidation of 7}

Compound 7 was submitted to epoxidation reaction employing the conditions that provided highest yield and ee for 11 (4 mol\% Jacobsen catalyst and $\mathrm{NaOCl}$ as oxidant without additives, entry 10 , Table 3). The epoxide 8 was stereoselectively obtained in trans conformation and moderate yield (Table 4). This could be expected according to above described findings for 11. However, the present result is relevant due to employed olefin have trans-configuration. Besides, the substituent groups on 7 can limit the interaction among $\mathrm{C}=\mathrm{C}$ and metallic center in the active species, $[\mathrm{Mn}=\mathrm{O}($ salen)]. Moreover, oxygen atoms in the substituent groups of 7 can involve negative effects on catalytic performance by interaction with the highly oxophilic manganese atom. Diastereomeric ratio was determined such as it was done for the compound 12 (Fig. 7). This determination was accomplished by measuring of the integrals of the ${ }^{1} \mathrm{H}$-NMR signals at 1.46 and $1.13 \mathrm{ppm}$, which 
Table 3. Jacobsen epoxidation of $\mathbf{1 1}$ under different reaction conditions ${ }^{\mathrm{a}}$.

\begin{tabular}{|c|c|c|c|c|c|c|}
\hline Entry & Solvent & Oxidant $^{b}$ & Additive $^{c}$ & Time(h) & Yield $^{d}(\%)$ & $e^{e}(\%)$ \\
\hline 1 & $\mathrm{CH}_{2} \mathrm{Cl}_{2}$ & $\mathrm{H}_{2} \mathrm{O}_{2}$ & -- & $>6$ & -- & -- \\
\hline 2 & $\mathrm{CH}_{2} \mathrm{Cl}_{2}$ & $\mathrm{NaOCl}$ & $\mathrm{NH}_{4} \mathrm{AcO}$ & 24 & 36.0 & 16.2 \\
\hline 3 & $\mathrm{CH}_{2} \mathrm{Cl}_{2}$ & $\mathrm{H}_{2} \mathrm{O}_{2}$ & $\mathrm{NH}_{4} \mathrm{AcO}$ & 24 & 15.2 & n.d. \\
\hline 4 & $\mathrm{CH}_{2} \mathrm{Cl}_{2}$ & $\mathrm{NaOCl}$ & Imidazole & 7 & 19.0 & 3.8 \\
\hline 5 & $\mathrm{CH}_{2} \mathrm{Cl}_{2}$ & $\mathrm{H}_{2} \mathrm{O}_{2}$ & Imidazole & 7 & 9.8 & n.d. \\
\hline 6 & $\mathrm{CH}_{2} \mathrm{Cl}_{2}$ & $\mathrm{H}_{2} \mathrm{O}_{2}^{\mathrm{f}}$ & Imidazole & 24 & 4.5 & n.d. \\
\hline 7 & $\mathrm{CH}_{2} \mathrm{Cl}_{2}$ & $\mathrm{NaOCl}$ & Pyridine & 4 & 50.3 & 9.7 \\
\hline 8 & $\mathrm{CH}_{2} \mathrm{Cl}_{2}$ & $\mathrm{NaOCl}$ & Pyridine $^{9}$ & 2 & 59.0 & 9.8 \\
\hline 9 & $\mathrm{CH}_{2} \mathrm{Cl}_{2}$ & $\mathrm{H}_{2} \mathrm{O}_{2}$ & Pyridineg & 6 & 2.1 & n.d. \\
\hline 10 & $\mathrm{CH}_{2} \mathrm{Cl}_{2}$ & $\mathrm{NaOCl}$ & -- & 6 & 67.9 & 19.8 \\
\hline 11 & {$[\mathrm{OPIC}]\left[\mathrm{BF}_{4}\right]$} & $\mathrm{NaOCl}$ & -- & 24 & 16.1 & 15.4 \\
\hline 12 & {$[\mathrm{OPIC}]\left[\mathrm{BF}_{4}\right]$} & $\mathrm{NaOCl}$ & Pyridine $^{g}$ & 6 & 29.5 & 9.2 \\
\hline 13 & {$[\mathrm{OPIC}]\left[\mathrm{BF}_{4}\right]$} & $\mathrm{H}_{2} \mathrm{O}_{2}^{\mathrm{f}}$ & -- & 24 & 10.8 & n.d. \\
\hline 14 & [BMIM] $\left[\mathrm{BF}_{4}\right]-\mathrm{CH}_{2} \mathrm{Cl}_{2}$ & $\mathrm{NaOCl}$ & -- & 6 & 48.3 & 4.2 \\
\hline 15 & {$[\mathrm{BMIM}]\left[\mathrm{PF}_{6}\right]$} & $\mathrm{NaOCl}$ & Pyridine ${ }^{g}$ & 6 & 9.6 & n.d. \\
\hline 16 & {$[\mathrm{EMIM}]\left[\left(\mathrm{CF}_{3} \mathrm{SO}_{2}\right)_{2} \mathrm{~N}\right]$} & $\mathrm{NaOCl}$ & Pyridine $^{g}$ & 6 & 19.5 & 3.2 \\
\hline 17 & {$[\mathrm{EMIM}]\left[\mathrm{SO}_{4} \mathrm{Et}\right]$} & $\mathrm{NaOCl}$ & Pyridine ${ }^{9}$ & 6 & 15.4 & 0.2 \\
\hline 18 & $\mathrm{CH}_{3} \mathrm{CN}-\left(\mathrm{CH}_{3}\right)_{2} \mathrm{CO}$ & $\mathrm{NaOCl}$ & $\left(\mathrm{CH}_{3}\right)_{4} \mathrm{NCl}$ & 24 & 5.5 & n.d. \\
\hline
\end{tabular}

a $4 \mathrm{~mol} \%$ of $(R, R)$-catalyst; ${ }^{\text {b }} 2$ eq of $\mathrm{NaOCl}$ or 3 eq of $\mathrm{H}_{2} \mathrm{O}_{2} ;{ }^{c} 2$ eq; ${ }^{\mathrm{d}}$ quantification by RP-HPLC; ${ }^{e}$ determined by chiral $\mathrm{HPLC} ;{ }^{\mathrm{f}} 10$ eq; ${ }^{g} 5$ eq

can be attributed to $\mathrm{H}$ atom from the methyl group in phenyl oxiranes (Tian et al., 2002). On the other hand, the product 8 resulted to be decomposed on silica gel, so that neutral alumina was required to purification process (Table 4). One recycling process of the catalyst was also attempted finding comparable yield and stereoselectivity (entry 3, Table 4).
The obtained product 8 was established as a transepoxide according to the coupling constant between $\mathrm{H}-1$ and $\mathrm{H}-2(\mathrm{~J}=2 \mathrm{~Hz})$ and comparing it with literature (Solladié-Cavallo et al., 2000). Although enantiomeric excess cannot be determined, optical rotation was evident. Therefore, some asymmetric induction was achieved. 


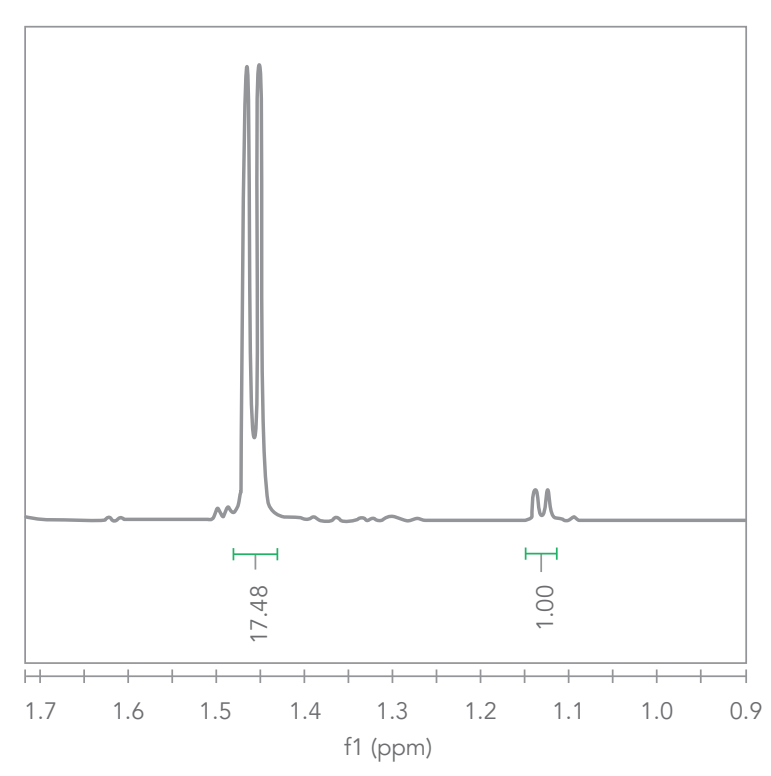

Figure 7. Diastereomeric ratio determination to epoxidation of $\mathbf{7}$ by ${ }^{1} \mathrm{H}-\mathrm{NMR}$ signals of its methyl group.

\section{Ring opening epoxide}

The nucleophilic attack on the epoxide 8 was attempted under several reaction conditions (Table 5). Two major products were identified as originated from nucleophilic substitution reactions, both obtained in very different yields and conversions. An undesired product could be afforded by side radical reactions. Salen complexes (Jacobsen, 2000; Pastor and Yus, 2005; Gupta and Sutar, 2008) and bismuth

Table 4. Jacobsen epoxidation of 7

\begin{tabular}{cccc}
\hline Entry & $\begin{array}{c}\text { Stationary } \\
\text { phase }\end{array}$ & $\begin{array}{c}\text { Yield } \\
\text { (\%) }\end{array}$ & $\begin{array}{c}\text { trans:cis } \\
\text { ratio }^{a}\end{array}$ \\
\hline 1 & Silica gel & 11.9 & -- \\
\hline 2 & Neutral alumina & 43.5 & $94.5: 1$ \\
\hline $3^{\text {b }}$ & Neutral alumina & 40.3 & $95.6: 1$ \\
\hline
\end{tabular}

aiastereomeric ratio determined by integration of ${ }^{1} \mathrm{H}-\mathrm{NMR}$ signals of the methyl groups; ${ }^{b}$ double addition of substrate and oxidant (one only catalyst load). salts (Ollevier and Lavie-Compin, 2004) have been employed in ring opening epoxides by aromatic amines. Therefore, Jacobsen catalyst and bismuth nitrate (entry 7 and 9, respectively; Table 5) were tested in ring opening epoxide. Nevertheless, no significant improve were detected respect to entry 1 (Table 5). The use of previously prepared isoeugenol sodium salt (entries 2 and 3, Table 5) not showed the formation of 9. Acetonitrile was attempted as solvent (entry 4, Table 5) but selectivity of the reaction was completely changed obtaining thus other than the desired product. In contrast, the use of acetonitrile as medium including a weak base (entry 10, Table 5) exhibited a very different performance (neolignan was found in very low yield). Poor results were observed when reaction was carried out at reflux temperature. Thereof, room temperature was also tested (entries 5-9, Table 5). However, significant yields were not exhibited or a great number of side products were observed. Neolignan 9 was only obtained by alcoholic potassium hydroxide under reflux (entry 1, Table 5) although only $23 \%$ yield was reached. A common ionic liquid was also tested (entry 8, Table 5) due to his known powerful solvation properties and uses in nucleophilic substitution reactions (Wasserscheid and Welton, 2008; Jorapur and Chi, 2006; Wheeler et al., 2001), but reaction selectivity was turned toward another product.

\section{Reductive hydrogenolysis of 9}

In order to accomplish the proposed synthetic strategy, reductive hydrogenolysis process was attempted. The adopted methodology was based on typical hydrogenolysis reports employing hydrogen and palladium/carbon catalyst (Xia et al., 2010; Llàcer et al., 2006). The compound 10 was obtained in low yield. Not greater than atmospheric pressure of hydrogen was used here, but the catalytic process resulted in debenzylation companied with hydrogenation of the double bond in the second 
Table 5. Ring opening epoxide 8 under different reaction conditions.

\begin{tabular}{ccccc}
\hline Entry & Reagents & Solvent & Condition & $\begin{array}{c}\text { Product } \\
\text { formation* }\end{array}$ \\
\hline 1 & Isoeugenol $+\mathrm{KOH}$ & $\mathrm{EtOH}$ & Reflux & 9 \\
\hline 2 & Sodium Isoeugenolate & 1,3-dioxolane & Reflux & -- \\
\hline 3 & Sodium Isoeugenolate & $\mathrm{MeCN}$ & Reflux & - - \\
\hline 4 & Isoeugenol $+\mathrm{KOH}$ & $\mathrm{MeCN}$ & Reflux & $\mathrm{S}_{\mathrm{a}}$ \\
\hline 5 & Isoeugenol $+\mathrm{KOH}$ & $\mathrm{EtOH}$ & r.t. & 9 \\
\hline 6 & Isoeugenol $+\mathrm{Et}_{3} \mathrm{~N}$ & $\mathrm{MeCN}$ & r.t. & 9 \\
\hline 7 & Isoeugenol $+\mathrm{Jacobsen}$ cat. & $\mathrm{TBME}$ & r.t. & $9+\mathrm{S}_{\mathrm{a}}$ \\
\hline 8 & Isoeugenol $+\mathrm{KOH}^{\mathrm{E}}$ & $\mathrm{EtOH}+[\mathrm{BMIM}]\left[\mathrm{BF}_{4}\right]$ & r.t. & $\mathrm{S}_{\mathrm{b}}$ \\
\hline 9 & Isoeugenol $+\mathrm{Bi}\left(\mathrm{NO}_{3}\right)_{3}$ & $\mathrm{Et} \mathrm{O}_{2}$ & r.t. & 9 \\
\hline 10 & Isoeugenol $+\mathrm{Na}_{2} \mathrm{CO}_{3}$ & $\mathrm{MeCN}$ & Reflux & 9 \\
\hline
\end{tabular}

* $\mathrm{S}_{\mathrm{a}}$ and $\mathrm{S}_{\mathrm{b}}$ represent main products other than 9 according to TLC.

phenylpropene unit introduced. Therefore, the isolated product corresponded to the hydrogenated derivative of machilin D. Compound 10 can be characterized as threo-isomer due to coupling constant between $\mathrm{H}-1$ and $\mathrm{H}-2$ of $8.0 \mathrm{~Hz}$ and confirmed with chemical shift for $\mathrm{C}-3$ at $17.9 \mathrm{ppm}$ (Herrera et al., 1984). Nevertheless, erythro-conformation would be expected from a trans-epoxide if reaction conditions had been those to SN2 reaction. The threo-conformation suggested a SN1 mechanism in this reaction and let us to propose the loss of the erythro-isomer across the purification step.

In conclusion, we have developed an inexpensive and diastereoselective approach to obtain $7^{\prime}, 8^{\prime}$-dihydromachilin D in only four steps in 3.9\% overall yield for the first time. An enantiomerically enriched epoxide from Jacobsen epoxidation was used as key intermediate. The present methodology can be extended to any other natural and not natural 8-O-4' neolignan by replacing the phenylpropene at the first step and/or at the ring opening epoxide step.

\section{ACKNOWLEDGEMENT}

Authors are grateful to Departamento de Química at Universidad Nacional de Colombia for the financial and technical support. We thank to Prof. Dr. Antonio Togni (ETHZ) for Jacobsen catalyst donation. 


\section{REFERENCES}

1. Aveniente M., Pinto E.F., Santos L.S., RossiBergmann B., Barata L.E.S. 2007. Structure-activity relationship of antileishmanial neolignan analogues. Bioorganic \& Medicinal Chemistry, 15:7337-7343.

2. Bahramian B., Mirkhani V., Tangestaninejad S., Moghadamb M. 2006. Catalytic epoxidation of olefins and hydroxylation of alkanes with sodium periodate by water-soluble manganese(III) salen. Journal of Molecular Catalysis A: Chemical, 244:139-145.

3. Barata L.E.S., Baker P.M., Gottlieb O.R., Rúveda E.A. 1978. Neolignans of Virola surinamensis. Phytochemistry, 17:783-786.

4. Barrero A.F., Alvarez-Manzanedaan E.J., Chahboun R. 1998. Synthesis of Wiedendiol-A and Wiedendiol-B from labdane diterpenes. Tetrahedron, 54:5635-5650.

5. Baudequin C., Baudoux J., Levillain J., Cahard D., Gaumont A.C., Plaquevent J.C. 2003. Ionic liquids and chirality: opportunities and challenges. Tetrahedron: Asymmetry, 14:3081-3093.

6. Bernal F.A. and Cuca Suárez L.E. 2009. Chemical constituents from Iryanthera ulei Warb. Biochemical Systematics and Ecology, 37:772-775.
7. Buchi G., Foulkes D.M., Kurono M., Mitchell G.F., Schneider R.S. 1967. The total synthesis of racemic Aflatoxin B1. Journal of the American Chemical Society, 89:6745-6753.

8. Cavallo L. and Jacobsen H. 2003. Electronic effects in (salen)Mn-based epoxidations catalysts. Journal of Organic Chemistry, 68:6202-6207.

9. Chang H-T. and Sharpless K.B. 1996. Molar scale synthesis of enantiopure stilbene oxide. Journal of Organic Chemistry, 61:6456-6457.

10. Clarke E.F., McGarrigle E.M., Gilheany D.G. 2005. Cr-Salen mediated asymmetric epoxidation of alkenes: rational complex design and substrate scope of catalyst. ARKIVOC, I:30-38.

11. Durand J., Teuma E., Gómez M. 2007. Ionic liquids as a medium for enantioselective catalysis. Comptes Rendus Chimie, 10:152-177.

12. Gu W.X., Chen X.C., Pan X.F., Chan A.B.S., Yang T-K. 2000. First enantioselective syntheses of (2R,3R)- and (2S,3S)-3-(4-hydroxy3-methoxyphenyl)-2-hydroxymethyl-1,4benzodioxan-6-carbaldehyde. Tetrahedron: Asymmetry, 11:2801-2807.

13. Gupta K.C. and Sutar A.K. 2008. Catalytic activities of Schiff base transition metal 
complexes; Coordination Chemistry Reviews, 252:1420-1450.

14. Hada S., Hattori M., Tezuka Y., Kikuchi T., Namba T. 1988. New neolignans and lignans from the aril of Myristica fragrans. Phytochemistry, 27:563-568.

15. Herrera A.C., Zacchino S., Badano H., González M., Rúveda E.A. 1984. ${ }^{13} \mathrm{C}$ NMR spectral and conformational analysis of 8-O-4' neolignans. Phytochemistry, 23:2025-2028.

16. Imuta M. and Ziffer H. 1979. Synthesis and physical properties of a series of optically active substituted trans-stilbene oxides. Journal of Organic Chemistry, 44:2505-2509.

17. Jacobsen E.N. 2000. Asymmetric catalysis of epoxide ring-opening reactions. Accounts of Chemical Research, 33:421-431.

18. Jacobsen E.N., Zhang W., Muci A.R., Ecker J.R., Den L. 1991. Highly enantioselective epoxidation catalysts derived from 1,2-diaminocyclohexane. Journal of the American Chemical Society, 113:7063-7064.

19. Jorapur Y.R.and Chi D.Y. 2006. lonic liquids: an environmentally friendly media for nucleophilic substitution reactions. Bulletin of the Korean Chemical Society, 27:345-354.
20. Khavrutskii I.V., Musaev D.G., Morokuma K. 2004. Epoxidation of unfunctionalized olefins by $\mathrm{Mn}$ (salen) catalyst using organic peracids as oxygen source: A theoretical study. Proceedings of the National Academic of Sciences, 101:5743-5748.

21. Kumar A. 2007. Epoxidation of alkenes with hydrogen peroxide catalyzed by 1-methyl-3-butylimidazoliumdecatungstate in ionic liquid. Catalysis Communications, 8:913-916.

22. Liao S. and List B. 2009. Asymmetric Counteranion-Directed Transition-Metal Catalysis: Enantioselective Epoxidation of Alkenes with Manganese(III) Salen Phosphate Complexes. Angewandte Chemie International Edition, 48:1-5.

23. Llàcer E., Romea P., Urpí F. 2006. Studies on the hydrogenolysis of benzyl ethers. Tetrahedron Letters, 47:5815-5818.

24. McGarrigle E.M., Gilheany D.G. 2005. Chromium and manganese salen promoted epoxidation of alkenes. Chemical Reviews, 105:1563-1602.

25. Miessler G.L. and Tarr D.A. 2004. Inorganic Chemistry. Third Edition. Pearson Education South Asia Pte Ltd., Jurong, Singapore. 697p. 
26. Nocito I., Castelli M.V., Zacchino S.A., Serra E. 2007. Activity of 8.O.4'-neolignans against Trypanosoma cruzi. Parasitology Research, 101:1453-1457.

27. Ollevier T. and Lavie-Compin G. 2004. Bismuth triflate-catalyzed mild and efficient epoxide opening by aromatic amines under aqueous conditions. Tetrahedron Letters, 45:49-52.

28. Pârvulescu V.I., Hardacre C. 2007. Catalysis in ionic liquids. Chemical Reviews, 107:2615-2665.

29. Pastor I.M. and Yus M. 2005. Asymmetric ring opening of epoxides. Current Organic Chemistry, 9:1-29.

30. Phan M.G., Phan T.S., Matsunami K., Otsuka H. 2006. New neolignans and lignans from Vietnamese medicinal plant Machilus odoratissima Nees. Chemical \& Pharmaceutical Bulletin, 54:380-383

31. Pinheiro A.A.C., Borges R.S., Santos L.S., Alves C.N. 2004. A QSAR study of 8.0.4-neolignans with antifungal activity. Journal of Molecular Structure: THEOCHEM, 672:215-219.

32. Pinto L.D., Dupont J., de Souza R.F., BernardoGusmão K. 2008. Catalytic asymmetric epoxidation of limonene using manganese Schiffbase complexes immobilized in ionic liquids. Catalysis Communications, 9:135-139.

33. Pond F.J. and Beers F.T. 1897. Derivatives of eugenol. Journal of the American Chemical Society, 19:825-831.
34. Reddy P.R. and Das B. 2014. The first stereoselective total synthesis of a new antitumour and anti-inflammatory neolignan, surinamensinol A. RSC Advances, 4:7432-7434.

35. Sadhu S.K., Okuyama E., Fujimoto H., Ishibashi M. 2003. Separation of Leucas aspera, a medicinal plant of Bangladesh, guided by prostaglandin inhibitory and antioxidant activities. Chemical and Pharmaceutical Bulletin, 51:595-598.

36. Sefkow M. 2003. The stereoselective synthesis of neolignans. Synthesis, 17:2595-2625.

37. Shimomura H., Sashida Y., Oohara M. 1987. Lignans from Machilus thunbergii. Phytochemistry, 26:1513-1515.

38. Skarżewski J., Gupta A., Vogt A. 1995. Influence of additional ligands on the two-phase epoxidation with sodium hypochlorite catalyzed by (salen) manganese (III) complexes. Journal of Molecular Catalysis A: Chemical, 103:L63-L68.

39. Solladié-Cavallo A., Bouérat L., Roje M. 2000. Asymmetric synthesis of trans-disubstituted aryl-vinyl epoxides: a p-methoxy effect. Tetrahedron Letters, 41:7309-7312.

40. Song C.E., Roh E.J. 2000. Practical method to recycle a chiral (salen)Mn epoxidation catalyst by using an ionic liquid. Chemical Communications, 837-838.

41. Song C.E., Yoon M.Y., Choi D.S. 2005. Significant improvement of catalytic efficiencies in 
ionic liquids. Bulletin of the Korean Chemical Society, 26:1321-1330

42. Tang X., Tang Y., Xu G., Wei S., Sun Y. 2008. Highly enantioselective epoxidation of styrene and $\alpha$-methylstyrene catalyzed by new doublyimmobilized chiral (salen)Mn(III) catalysts. Catalysis Communications, 10:317-320.

43. Tian H., She X., Yu H., Shu L., Shi Y. 2002. Designing new chiral ketone catalysts. Asymmetric epoxidation of cis-olefins and terminal olefins. Journal of Organic Chemistry, 67:2435-2446.

44. Tsai I-L., Hsleh C-F., Duh C-Y., Chen I-S. 1996. Cytotoxic neolignans from Persea obovatifolia. Phytochemistry, 43:1261-1263.

45. Wasserscheid P. and Welton T. (ed). 2008. Ionic Liquids in Synthesis. $2^{\text {nd }}$ edition. WILEY-VCH Verlag GmbH \& Co. KGaA, Weinheim, 721p.

46. Welton T. 2004. Ionic liquids in catalysis. Coordination Chemistry Reviews, 248:2459-2477.

47. Wheeler C., West K.N., Liotta C.L., Eckert C.A. 2001. Ionic liquids as catalytic green solvents for nucleophilic displacement reactions. Chemical Communications, 887-888.

48. Xia Y., Chang L., Ding Y., Jiao B. 2010. Asymmetric synthesis of erythro-8-O-4'-neolignan Machilin C. Mendeleev Communications, 20:151-152.

49. Xia Y-M., Wang W. 2011. Asymmetric synthesis of the natural erythro-(1R,2S)-8-O-4'-neolignan myrislignan. Monatshefte für Chemie, 142:93-96.

50. Xia Y-M., Wang W., Guo Y-L., Li J-F. 2010. Asymmetric synthesis of 8-O-4'-neolignan perseal B. Turkish Journal of Chemistry, 34:375-380.

51. Zhang W. and Jacobsen E.N. 1991. Asymmetric olefin epoxidation with sodium hypochlorite catalyzed by easily prepared chiral $\mathrm{Mn}$ (III) salen complexes. Journal of Organic Chemistry, 56:2296-2298.

52. Zhang W., Loebach J.L., Wilson S.R., Jacobsen E.N. 1990. Enantioselective epoxidation of unfunctionalized olefins catalyzed by (Salen)Manganese complexes. Journal of the American Chemical Society, 112:2801-2803.

53. Zhao D., Wu M., Kou Y., Min E. 2002. Ionic liquids: applications in catalysis. Catalysis Today, 74:157-189.

54. Zheng X.M., Qi Y.X., Zhang X.M., Suo J.S. 2004. Chiral Salen Manganese complex immobilized on SBA-15: A new heterogenized enantioselective catalyst for the epoxidation of alkenes. Chinese Chemical Letters, 15:655-658. 